\title{
Prevalence of gestational diabetes mellitus in a suburban District in Sri Lanka: a population based study
}

B H Sudasinghe ${ }^{1}$, P S Ginige ${ }^{3}$, C N Wijeyaratne ${ }^{2}$

\begin{abstract}
Introduction GDM is a leading metabolic cause of morbidity to mother and offspring. Determining its prevalence is important for health planning and implementation.

Objective Assess prevalence of GDM in the District of Gampaha.

Method Community based cross-sectional study was conducted in women attending field-based ante-natal clinics in two Medical Officer of Health $(\mathrm{MOH})$ areas between January 2014 to March 2015.

Consecutive women were recruited by cluster sampling with probability proportionate to size using strict exclusion criteria. GDM diagnosis was based on fasting $75 \mathrm{~g}$ OGTT, WHO 1999. All responders underwent $2 \mathrm{hr}$ PPBS in first trimester- $>200 \mathrm{mg} / \mathrm{dl}$ with symptoms identified as abnormal, probably diabetes in pregnancy (DIP); those $>120$ and $<200 \mathrm{mg} / \mathrm{dl}$ proceeded to OGTT before 16 weeks POA; all negatives were tested by OGTT between 24-28 weeks. Negatives for GDM at 24-28 weeks underwent OGTT between $32-36$ weeks; venous plasma glucose tested by accredited laboratory.

Results Sample consistedof 160, non-response 4.2\% (67); 1533 underwent $2 \mathrm{hr}$ PPBS with 40 exceeding 120mg: 4 $>200$ mg diagnosed as GDM / DIP, 36 (PPBS >120< 200 $\mathrm{mg}$ ) underwent OGTT before 16 weeks with $15 \mathrm{GDM}$. One hundred and thirty four (8.38\%) miscarried including one with early abnormal OGTT. Of 1381 eligible for OGTT (2428 weeks) 150 had GDM (10.86\%). Only 344 (27.94\% of normal 1231) consented for third trimester OGTT, of whom 25 had GDM- yielding a total of 194 with GDM (13.9\%).

Conclusion The current community prevalence of GDM in the suburban Gampaha District, Sri Lanka is high.
\end{abstract}

Ceylon Medical Journal 2016; 61: 149-153

http://doi.org/10.4038/cmj.v61i4.8379

\section{Introduction}

Gestational diabetes mellitus (GDM) is a common metabolic disorder of pregnancy and it is the leading cause of short and long term morbidity to mother and offspring. It is associated with a significantly increased risk of fetal macrosomia, shoulder dystocia, birth injuries as well as neonatal hypoglycemia and hyperbilirubinemia [1]. Even borderline GDM has been linked with an increased frequency of perinatal complications, with the maternal glycaemia demonstrating a continuum effect on perinatal outcome [2]. In GDM, concurrent pregnancy-induced hypertension further increases the adverse outcomes [1]. Babies born to mothers with GDM are at increased risk of developing obesity, diabetes and metabolic syndrome in childhood and early adulthood [1]. Further, studies have demonstrated an increased risk of future GDM in girls born to mothers with GDM affecting their index pregnancies [3]. Pregnancies complicated by GDM have higher rates of caesarean sections and induced deliveries, with approximately 10-30\% developing pre-eclampsia [1]. Women with GDM have a high risk of developing type 2 diabetes (DM) within five years postpartum with a doubling of the risk after the first five years [4]. In South India, the reported incidence of postpartum DM among women with history of previous GDM is even higher within the first five years with over $90 \%$ being affected within 10 years of delivery [5]. After delivery, women with GDM often have an increased risk of developing metabolic syndrome, which is also seen in South Asian women [1, 6-8].

The prevalence of GDM varies across the world, with differing diagnostic criteria causing difficulty in comparing prevalence rates between geographical regions and ethnic groups. However, an increasing prevalence is noted throughout the world [9-11]. A high prevalence of GDM is reported in India, with urban (17.8\%), semi urban (13.8\%) and rural (9.9\%) variations based on WHO 1999 criteria [12]. The Sri Lankan data mirrors this with an approximate doubling of prevalence over seven years

Departments of ${ }^{1}$ Community Medicine and ${ }^{2}$ Obstetrics and Gynaecology, Faculty of Medicine, University of Colombo, ${ }^{3}$ Epidemiological Unit, Colombo, Sri Lanka.

Correspondence: SPBHS, e-mail: <buddhikasudasinghe@yahoo.com>. Received 21 June 2016 and revised version accepted 19 October 2016. and reproduction in any medium, provided the original author and source are credited. 
from $5.5 \%$ in 1998 to $10.3 \%$ in 2004 [13,14]. No reports of community prevalence of GDM have been published from Sri Lanka after 2004. Nevertheless, urbanization and unhealthy lifestyle patterns have increased the risk, which requires quantification to enable health planners to implement timely appropriate screening and preventive measures. Hence the current study aimed to assess the community prevalence of GDM in rural/suburban areas within the district of Gampaha, Western Province of Sri Lanka.

\section{Methods}

A community based cross sectional study was conducted among pregnant women in field ante-natal clinic settings in Medical Officer of Health (MOH) areas of Dompe and Gampaha within the District of Gampaha, Sri Lanka from January 2014 to March 2015. The District of Gampaha consists of $16 \mathrm{MOH}$ areas, each area supervised by a Medical Officer of Health. Total population in the two selected $\mathrm{MOH}$ areas were 351672 [15]. The study population consisted of women confirmed biochemically as pregnant with a period of amenorrhoea (POA) less than 12 weeks at the time of registration by the Public Health Midwife (PHM). Those diagnosed as having DM before pregnancy, prescribed diabetogenic drugs such as steroids, anti-epileptics and anti-psychotics, having severe co-morbidities or mental subnormality were excluded from the study at recruitment. The required sample size was 1324 with 1.96 of standard normal deviation for $5 \% \alpha$ error, 0.025 precision and 2.8 design effect. Most recent community prevalence of GDM in Sri Lanka (8.4\%) was used for calculating the sample size [14]. A further $10 \%$ was added to compensate for non-responders and another $10 \%$ allowance made for miscarriages. The final calculated sample size was 1600 .

The sample was selected in three stages; firstly, two $\mathrm{MOH}$ areas were randomly selected from the 16 areas. Secondly, within the selected $\mathrm{MOH}$ areas, all the PHM areas $(n=88)$ with cumulative population were listed. The cluster size was considered as 20 . This number was determined based on feasibility of recruiting the required total sample within the first 3 months of the study and local logistics. Thirdly, after selection of the first cluster randomly, 80 clusters were selected according to probability proportionate to size of the PHM areas. Finally, from the selected PHM areas, the Pregnancy Register was used to select pregnant women less than a POA of 12 weeks. First eligible name was selected randomly. Thereafter; every consecutive name until achieving the required number was recruited, adhering to the inclusion and exclusion criteria.

All registered pregnant women were requested to attend the identified field clinics. A survey carried out to assess the completeness of registration of pregnant women by the principal investigator revealed that pregnant women registration rate was over $98 \%$ in these two $\mathrm{MOH}$ areas.
Data were gathered from all consenting pregnant women using an interviewer administered structured questionnaire. The 2 hour post prandial plasma glucose ( $2 \mathrm{hr}$ PPBS) test following a standard Sri Lankan meal and fasting $75 \mathrm{~g}$ oral glucose tolerance test ( $75 \mathrm{~g}$ OGTT) were chosen as the first trimester screening and diagnostic method respectively [16-19]. The $2 \mathrm{hr}$ PPBS cut off value of $120 \mathrm{mg} / \mathrm{dl}$ was determined as a proxy measure to detect probable previously unknown diabetic women, since this is the internationally recognised glycaemic target recommended for managing diabetes during pregnancy [20]. We selected women based on $2 \mathrm{hr}$ PPBS value exceeding $120 \mathrm{mg} / \mathrm{dl}$ as probable diabetes complicating pregnancy to be confirmed by the gold standard fasting $75 \mathrm{~g}$ OGTT performed in early pregnancy (before the prescribed timing of 24 weeks). GDM was diagnosed by WHO 1999 criteria (fasting plasma glucose value $\geq 126$ $\mathrm{mg} / \mathrm{dl}$ or 2 hour plasma glucose value of $\geq 140 \mathrm{mg} / \mathrm{dl}$ ) in 75 g OGTT to enable comparison with previous prevalence rates using the identical criteria [19].

All consenting participants were universally screened for GDM. Firstly, they underwent the $2 \mathrm{hr}$ PPBS test in the first trimester; where those with a value above $200 \mathrm{mg}$ were identified as having GDM (by WHO 1999 criteria) and most probably diabetes in pregnancy (DIP) and referred appropriately [21]. Those who had $2 \mathrm{hr}$ PPBS above $120 \mathrm{mg} / \mathrm{dl}$ but less than $200 \mathrm{mg}$ underwent fasting $75 \mathrm{~g}$ OGTT before 16 weeks of POA [16,17]. All mothers who had $2 \mathrm{hr}$ PPBS values $<120 \mathrm{mg} / \mathrm{dl}$ in $1^{\text {st }}$ trimester and those with $>120 \mathrm{mg} / \mathrm{dl}$ and $<200 \mathrm{mg} / \mathrm{dl}$ but with normal OGTT at 16 weeks underwent mandatory fasting $75 \mathrm{~g}$ OGTT between 24-28 weeks if they remained pregnant $[19,22]$. Those who were negative for GDM at 24-28 weeks underwent OGTT at 32-36 weeks. The $2 \mathrm{hr}$ PPBS and fasting $75 \mathrm{~g}$ OGTT testing were performed with venous plasma in an accredited laboratory.

Approval for the study was granted by the Ethics Review Committee (ERC) of the Medical Research Institute, Colombo. Written informed consent was obtained from all patients.

\section{Results}

The total number of pregnant women recruited for the study was 1600 . Non response rate was $4.2 \%(n=67)$ and 1533 underwent $2 \mathrm{hr}$ PPBS in first trimester (response rate $95.8 \%$ ). Forty had $2 \mathrm{hr}$ PPBS value $>120 \mathrm{mg} / \mathrm{dl}$, of them four had more than $200 \mathrm{mg} / \mathrm{dl}$ and were diagnosed as GDM/probable DIP. The remaining 36 (PPBS $\geq 120$ $\mathrm{mg} / \mathrm{dl} \leq 200 \mathrm{mg}$ ) underwent OGTT before 16 weeks of POA. Of them 15 had GDM. Ninteen pregnant women developed GDM before 16 weeks of POA (1.2\%). One hundred and thirty four $(8.4 \%)$ had mis-carriages and were excluded from the study except one who had an early abnormal OGTT prior to pregnancy loss. The total population eligible for OGTT between 24-28 weeks was 1381 , of them 150 had GDM (10.9\%). A total of 169 pregnant women in the study sample developed GDM before 28 weeks POA yielding a prevalence of $12.1 \%$. 
Total population eligible for OGTT at 32-36 weeks was 1231 but only $344(27.9 \%)$ of the eligible 1231 women consented for a third trimester OGTT. A further 25 were found to have GDM in the 3rd trimester. A total of 194 pregnant women had GDM, giving a prevalence of $13.9 \%$. Considering individual $\mathrm{MOH}$ areas, $10.9 \%$ and $16.1 \%$ of prevalence were noted in Dompe and Gampaha, respectively. Age specific prevalence of the 15-24 years was $5.5 \%(n=16), 13.2 \%(n=116)$ for $25-34$ years and $27.2 \%(n=62)$ for $35-49$ years.

The final sample consisted of 1400 participants, whose characteristics are shown in Table 1.

Table 1. Characteristics of the study population

\begin{tabular}{lll}
\hline Characteristic & Pregnant women & Pregnant women \\
& with GDM $(n=194)$ & without GDM \\
& Frequency $(\%)$ & (n=1206) \\
& & Frequency $(\%)$
\end{tabular}

\begin{tabular}{|c|c|c|}
\hline \multicolumn{3}{|l|}{ Age } \\
\hline 15- 24 years & $16(5.5 \%)$ & $276(94.5 \%)$ \\
\hline $25-34$ years & $116(13.2 \%)$ & $764(86.8 \%)$ \\
\hline $35-49$ years & $62(27.2 \%)$ & $166(72.8 \%)$ \\
\hline \multicolumn{3}{|l|}{ Ethnicity } \\
\hline Sinhala & $191(13.8 \%)$ & $1189(86.2 \%)$ \\
\hline Tamil & $0(0 \%)$ & $5(100.0 \%)$ \\
\hline Muslim & $3(20 \%)$ & $12(80 \%)$ \\
\hline \multicolumn{3}{|l|}{ Religion } \\
\hline Buddhism & $172(13.4 \%)$ & $1109(86.6 \%)$ \\
\hline Christian/Catholic & $19(18.6 \%)$ & $83(81.4 \%)$ \\
\hline Hindu & $0(0 \%)$ & $2(100 \%)$ \\
\hline Islam & $3(20 \%)$ & $12(80 \%)$ \\
\hline \multicolumn{3}{|l|}{ Level of education } \\
\hline Not schooled & $0(0 \%)$ & $1(100 \%)$ \\
\hline Grade 1-5 & $1(33.3 \%)$ & $2(66.7 \%)$ \\
\hline Grade 6-O/L & $45(14.4 \%)$ & $268(85.6 \%)$ \\
\hline Passed O/L & $38(9.7 \%)$ & $353(90.3 \%)$ \\
\hline Completed A/L & $80(15.9 \%)$ & $422(84.1 \%)$ \\
\hline Technical education & $3(18.8 \%)$ & $13(81.2 \%)$ \\
\hline \multicolumn{3}{|l|}{ Diploma, university } \\
\hline degree and above & $27(15.5 \%)$ & $147(84.5 \%)$ \\
\hline \multicolumn{3}{|c|}{ Monthly family income (SLR) } \\
\hline less than 10,000 & $12(15.2 \%)$ & $67(84.8 \%)$ \\
\hline $10,000-19,999$ & $43(11.6 \%)$ & $328(88.4 \%)$ \\
\hline $20,000-29,999$ & $54(13.2 \%)$ & $356(86.8 \%)$ \\
\hline $30,000-39,999$ & $38(13.6 \%)$ & $242(86.4 \%)$ \\
\hline $40,000-49,999$ & $17(14.5 \%)$ & $100(85.5 \%)$ \\
\hline Equal or above 50,000 & $30(21 \%)$ & $113(79 \%)$ \\
\hline \multicolumn{3}{|l|}{ Employment status } \\
\hline Yes & $69(15.1 \%)$ & $389(84.9 \%)$ \\
\hline No & $125(13.3 \%)$ & $817(86.7 \%)$ \\
\hline \multicolumn{3}{|l|}{ BMI } \\
\hline$<18.5$ & $23(8.5 \%)$ & $247(91.5 \%)$ \\
\hline $18.5-24.99$ & $89(11.9 \%)$ & $656(88.1 \%)$ \\
\hline $25.00-30.00$ & $67(21 \%)$ & $252(79 \%)$ \\
\hline$>30$ & $15(22.7 \%)$ & $51(77.3 \%)$ \\
\hline \multicolumn{3}{|c|}{ Parental history of diabetes } \\
\hline Yes & $91(23.5 \%)$ & $296(76.5 \%)$ \\
\hline No & $103(10.2 \%)$ & $910(89.8 \%)$ \\
\hline
\end{tabular}

Vol. 61, No. 4, December 2016
Among those with GDM ( $\mathrm{n}=194)$; mean age was $31.74 \pm 5.11$ years, $64(33 \%)$ were primigravid and 75 (38.7\%) were in their second, 38 (19.6\%) third, 11 (5.7\%) fourth and fifth $5(2.6 \%)$ pregnancies. Mean body mass index (BMI) was $24.20 \pm 4.58$ but $8.5 \%$ were underweight. Sixty seven (34.5\%) with GDM had maternal history of diabetes and $42(21.6 \%)$ had paternal diabetes history. Overall, 91 (46.9\%) participants with GDM had parental history of diabetes (one or both parent). Ten had past history of GDM; five in the first, three in second and one each in third and fourth pregnancies.

Univariate analysis revealed the following asso-

Table 2. Comparison between two MOH areas

\begin{tabular}{lll}
\hline Characteristic & $\begin{array}{l}\text { MOH Dompe } \\
(n=613)\end{array}$ & $\begin{array}{l}\text { MOH Gampaha } \\
(n=787)\end{array}$ \\
\hline Mean age & $28.7 \pm 5.33$ & $29.27 \pm 5.18$ \\
Mean BMI & $22.05 \pm 4.46$ & $22.95 \pm 4.40$ \\
$\begin{array}{l}\text { Maternal history } \\
\text { of diabetes }\end{array}$ & $16.2 \%$ & $21 \%$ \\
$\begin{array}{l}\text { Paternal history } \\
\text { diabetes }\end{array}$ & $10.8 \%$ & $13.5 \%$ \\
$\begin{array}{l}\text { Parental history } \\
\text { of diabetes }\end{array}$ & $24 \%$ & $30.5 \%$ \\
\begin{tabular}{l} 
Past history of GDM $1.5 \%$ \\
\hline
\end{tabular} & $1.5 \%$ \\
\hline
\end{tabular}

ciations- age $\geq 35$ years (OR 2.94; 95\% CI 2.09-4.15 $p<0.0001$, ), maternal overweight (BMI $\geq 25)$ and obesity $(\mathrm{BMI} \geq 30)(\mathrm{OR} 2.18$; 95\% CI 1.60-2.98 $p<0.0001$, ), father being diabetic (OR 2.29; 95\% CI 1.55-3.37 $p<0.0001$, ), mother being diabetic (OR 2.70; 95\% CI $1.94-3.77 p<0.0001$ ), parity (OR 1.45; 95\% CI 1.01-2.0 $p=$ 0.022 , ) and GDM in previous pregnancies (OR 5.90; $95 \%$ CI 2.47-14.10 $p<0.0001)$ were significantly associated with occurrence of GDM in the index pregnancy. In multivariate analysis, age $\geq 35$ years (OR 2.81; 95\% CI 1.96-4.04 $p<0.0001$,), maternal overweight (BMI $\geq$ $25)$ and obesity (BMI $\geq 30)$ (OR $1.6895 \%$ CI 1.21-2.35 $p=0.002$, ), father being diabetic (OR 1.65 ; 95\% CI 1.06$2.56 p=0.028$, ), mother being diabetic (OR 2.30; 95\% CI $1.62-3.26 p<0.0001$, ) and GDM in previous pregnancies (OR 4.58; 95\% CI 1.81-11.61 $p=0.001$ ) were identified as risk factors for GDM occurrence in the index pregnancy.

\section{Discussion}

The current prevalence of GDM in the District of Gampaha, Sri Lanka is high. Age more than 35 years, maternal overweight/obesity, parental diabetes and previous GDM were significantly associated with the GDM after adjusting for the confounding effect.

The current study confirms that rate of GDM has increased in Sri Lanka. In 1998, 5.5\% of a cohort of 721 
pregnant women attending antenatal clinics at Sri Jayawardenepura General Hospital were identified as affected using the $75 \mathrm{~g}$ OGTT and WHO criteria [13]. A community based study conducted in 2004 of 853 pregnant women in Homagama $\mathrm{MOH}$ area reported a rate of $8.4 \%$ ( $75 \mathrm{~g}$ OGTT and 1999 WHO criteria) with the rate increasing with maternal age $(<25$ years $3 \%, 25-35$ years $9.6 \%$ and $\square 35$ years $15.9 \%$ ) and the age standardised prevalence was $10.3 \%$ [14]. The current study shows a prevalence of $13.9 \%$ in a more rural setting that confirms the increasing trend of gestational diabetes. This is a $65.5 \%$ increase compared to prevalence of GDM in Homagama $\mathrm{MOH}$ area, Colombo in 2004 [14].

In India prevalence of GDM of $18.9 \%$ was reported from an antenatal clinic of a Government Maternity Hospital, Chennai among 891 pregnant women in their second or third trimester (OGTT and WHO 1999 criteria) [23]. A study carried out among 4151, 3960 and 3945 pregnant women in urban, semi urban and rural areas, respectively in South India (Tamil Nadu), reported $17.8 \%$ in urban, $13.8 \%$ in semi urban and $9.9 \%$ in rural areas. Of 1679 women with GDM, 1204 (72\%) were detected in the first visit and the remaining in subsequent visits [12]. Several studies have identified increasing maternal BMI as a significant risk factor for GDM [24-26]. BMI, family history of diabetes mellitus and age $\square 35$ years were found to be independent risk factors for GDM in other studies [27-29]. Findings from our study were compatible with these findings.

A limitation of the current study is the exclusion of those on prescribed diabetogenic drugs such as steroids, anti-epileptics and anti-psychotics, as well those with severe co morbidities, mental illnesses and pregnant women with miscarriages leading to a somewhat selected sample.

\section{Acknowledgement}

We thank Medical Officer Maternal and Child Health Gampaha, Medical Officers of Health, Public Health Nursing Sisters, Public Health Midwives Gampaha and Dompe $\mathrm{MOH}$ areas for their support.

\section{Conflicts of interest}

There are no conflicts of interest.

\section{Funding}

Medical Research Institute and Nirogi Maatha project supported by World Diabetic Foundation.

\section{References}

1. Kaaja R, Rönnemaa T. Gestational Diabetes: Pathogenesis and Consequences to Mother and Offspring. Rev Diabet Stud 2008; 5: 194-202.

2. International Association of Diabetes and Pregnancy Study Groups. International Association of Diabetes and Pregnancy Study Groups Recommendations on the Diagnosis and Classification of Hyperglycemia in Pregnancy, Diabetes Care 2010; 33: 676-82.

3. Carey RE. Benefits of Screening for and Treating GDM. Today's Dietitian 2010; 12: 14.

4. Bellamy L, Casas JP, Hingorani AD, Williams D. Type 2 diabetes mellitus after gestational diabetes: a systematic review and meta-analysis. Lancet 2009; 373: 1773-9.

5. Mahalakshmi MM, Bhavadharini B, Kumar M, et al. Clinical profile, outcomes, and progression to type 2 diabetes among Indian women with gestational diabetes mellitus seen at a diabetes center in south India. Indian $J$ Endocrinol Metab 2014; 18: 400-6.

6. Barquiel B, Herranz L, Hillman N, Burgos MA, Pallardo LF. Prepregnancy body mass index and prenatal fasting glucose are effective predictors of early postpartum metabolic syndrome in Spanish mothers with gestational diabetes. Metab Syndr Relat Disord 2014; 12: 457-63.

7. Xu Y, Shen S, Sun L, Yang H, Jin B, Cao X. Metabolic syndrome risk after gestational diabetes: a systematic review and meta-analysis. PLoS One 2014; 9: 87863.

8. Wijeyaratne CN, Waduge R, Arandara D, et al. Metabolic and polycystic ovary syndromes in indigenous South Asian women with previous gestational diabetes mellitus. BJOG 2006; 113: 1182-7.

9. Chamberlain C, Joshy G, Li H, Oats J, Eades S, Banks E. The prevalence of gestational diabetes mellitus among Aboriginal and Torres Strait Islander women in Australia: a systematic review and meta-analysis. Diabetes Metab Res Rev 2015; 31: 234-47.

10. Leng J, Shao P, Zhang C, et al. Prevalence of Gestational Diabetes Mellitus and Its Risk Factors in Chinese Pregnant Women: A Prospective Population-Based Study in Tianjin, China. PLoS One 2015; 10: 121029.

11. Chu SY, Abe K, Hall LR, Kim SY, Njoroge T, Qin C. Gestational diabetes mellitus: all Asians are not alike. Prev Med 2009; 49: 265-8.

12. Seshiah V, Balaji V, Balaji MS, et al. Prevalence of gestational diabetes mellitus in South India (Tamil Nadu) - a community based study. J Assoc Physicians India 2008; 56: 329-33.

13. Siribaddana SH, Deshabandu R, Rajapakse D, Silva K, Fernando DJ. The prevalence of gestational diabetes in a Sri Lankan antenatal clinic. Ceylon Med J 1998; 43: 88-91.

14. Ginige PS. Prevalence and Pregnancy Outcome of Gestational Diabetes Mellitus (GDM) in Homagama DDHS Area and Validation of Selected Screening Methods to Detect GDM. Post Graduate Institute of Medicine, University of Colombo, 2004.

15. Department of Census and Statistics. Districts Final reportsGampaha. Department of Census and Statistics, 2014. 
16. Ministry of Health. National Guidelines for Maternal Care. Family Health Bureau, 2013.

17. Sri Lanka College of Obstetrics and Gynaecology. Clinical Guideline. Sri Lanka J Obst Gynaecol 2014: 38-42.

18. American Diabetes Association. Definition, Detection, and Diagnosis. Diabetes Care 2004; 27: 88-90.

19. World Health Organization. Definition, Diagnosis and Classification of Diabetes Mellitus and its Complications. Geneva, 1999.

20. American Diabetes Association. Standards of medical care in diabetes - 2016. Diabetes Care 2016; 39: 1-106.

21. World Health Organization. Diagnostic Criteria and Classification of Hyperglycaemia First Detected in Pregnancy. WHO, 2013.

22. American Diabetes Association. Diagnosis and Classification of Diabetes Mellitus. Diabetes Care 2004; 27: 5-10.

23. Seshiah V, Balaji V, Balaji MS, Sanjeevi CB, Green A. Gestational diabetes mellitus in India. $J$ Assoc Physicians India 2004; 52: 707-11.

24. Martin KE, Grivell RM, Yelland LN, Dodd JM. The influence of maternal BMI and gestational diabetes on pregnancy outcome. Diabetes Res Clin Pract 2015; 108: 508-13.

25. Padmanabhan S, Wagstaff A, Tung V, Chan YF, Bartlett A, Lau SM. Increase in body mass index during pregnancy and risk of gestational diabetes. Diabetes Res Clin Pract 2014: 106: $79-82$.

26. Flores-Padilla L, Solorio-Páez IC, Melo-Rey ML, TrejoFranco J. Pregnancy and obesity: risk of developing gestational diabetes in the northern border area of Mexico. Gac Med Mex 2014; 150: 73-8.

27. Shuang W, Huixia Y. Analysis of the effect of risk factors at gestational diabetes mellitus. Zhonghua Fu Chan KeZa Zhi 2014; 49: 321-4.

28. Duman NM. Frequency of gestational diabetes mellitus and the associated risk factors. Pak J Med Sci 2015; 31: 194-7.

29. Khan R, Ali K, Khan Z. Socio-demographic Risk Factors of Gestational Diabetes Mellitus. PakJ Med Sci 2013; 29: 843-6. 